Article

\title{
Unveiling Assigned Amount Unit (AAU) Trades: Current Market Impacts and Prospects for the Future
}

\section{Elizabeth Lokey Aldrich ${ }^{1, *}$ and Cassandra L. Koerner ${ }^{2}$}

1 Sustainability Studies Department, The White Mountain School, 371 West Farm Road, Bethlehem, NH 03574, USA

2 Energy Policy Institute, Boise State University, 1910 University Drive, Boise, ID 83725, USA; E-Mail: cassiekoerner@boisestate.edu

* Author to whom correspondence should be addressed; E-Mail: lokey@colorado.edu; Tel.: +1-303-898-558.

Received: 13 December 2011; in revised form: 30 January 2012 / Accepted: 27 February 2012 / Published: 7 March 2012

\begin{abstract}
The sale of assigned amount units (AAUs) from countries whose emissions have declined since their baseline year under the Kyoto Protocol has led critics to be skeptical of carbon markets due to the lack of actual emission reductions that occur as a result of these trades. This policy review describes the historical context of AAU trading, current market price and volumes, and environmental and economic impacts of the current AAU trading rules. Options for how to handle current, and prevent the creation of future, surplus AAUs are discussed.
\end{abstract}

Keywords: assigned amount unit; green investment scheme; hot air; international emissions trading; post-2012; Kyoto Protocol

\section{Introduction}

Under the United Nations Framework Convention on Climate Change's (UNFCCC) Kyoto Protocol, developed countries and economies in transition, termed Annex B Parties, have individual emissions caps on their greenhouse gas emissions for 2008 through 2012. The caps are expressed as a fraction of a base year, 1990 for most countries. Each Party is issued Assigned Amount Units (AAUs), each of which corresponds to 1 metric ton of carbon dioxide $\left(\mathrm{CO}_{2}\right)$ equivalence, equal to its cap. To 
comply with its commitment, each party must retire AAUs or other compliance instruments called Emission Reduction Units (ERUs) and Certified Emission Reductions (CERs), which are created through projects which absorb or reduce emissions under Joint Implementation (JI) and the Clean Development Mechanism (CDM), in an amount equal to its actual emissions for the 2008-2012 period. On a side note, CDM projects are hosted by developing countries while JI projects are hosted by either developed countries or Economies in Transition.

Trading of AAUs, CERs, and ERUs, known as International Emission Trading (IET), has been a key element of the cost-containing flexible mechanisms of the Kyoto Protocol and could prove to be a useful tool in the future. However, trading of AAUs from countries whose emissions have declined since their baseline year under the Kyoto Protocol has led critics to be skeptical of carbon markets due to the lack of actual emission reductions that occur as a result of these trades.

Green investment schemes (GISs) are meant to try to allay the fears of those that think there is no environmental integrity in AAU trading; these schemes use the proceeds of AAU trades to create projects that absorb or reduce greenhouse gases [1]. However, GISs have no required criteria for crediting, and actual determination of what qualifies as a GIS is left up to the discretion of the buying and selling countries. Inconsistent application of GISs as AAU trades ramp up toward 2012 when the Kyoto Protocol ends and post-2012 during the next global greenhouse gas accord or second Kyoto compliance period could erode the price of emission reductions and allowances worldwide and may elicit a harsh rebuke from those concerned with reductions in current emissions.

The wide-ranging results of AAU trades include the promotion of projects that encourage emission reductions but do not always ensure them on a one-to-one basis; creation of projects that attempt to yield an emission reduction for each AAU sold; and satisfaction of Kyoto targets with below-market priced permits to pollute that do not represent any emission reductions. We argue that policy makers need to clearly define the goal of AAU trading as (1) a way to address current carbon market failures through promotion of "soft" greening projects; (2) a means to promote investment in a selling country; (3) a trade that must be accompanied by a one-to-one emission reduction project; or (4) a method of promoting cost containment in the next global agreement and create an accord that effectively achieves the goal selected.

This paper will describe the historical context of AAU trading and the current market price and volumes. Then, the environmental and economic impacts of the current AAU trading rules will be illuminated. Finally, options for how to handle the current and future surplus AAUs that could be created will be discussed.

\section{AAU Background}

Under the Kyoto Protocol's Article 17, IET is meant to provide a flexible mechanism that allows countries to meet their emission reduction targets while providing cost containment. IET is based on the principle that the least-cost emission reductions can be used to meet reduction targets since greenhouse gases mix evenly in the atmosphere and have the same warming potential regardless of where they are released. At the start of the Kyoto compliance period in 2008, AAUs were allocated to each country based on their emissions in a baseline year and their individual reduction targets. At the 
end of the Kyoto Protocol's first compliance period in 2012, each country will have to surrender enough AAUs to cover their emissions over the five year period.

The baseline year of 1990 was selected for most countries except those in the process of transitioning to a market economy. These transitioning countries were able to choose their baseline year [2]. The year 1990 was particularly advantageous to parts of Eastern Europe and Russia, which had a heavy industrial year before the Soviet Union dissolved completely in 1991. In fact, Russia's decision to ratify the Kyoto Protocol was based on the selection of 1990 as a baseline year; it was well-known among both Russian bureaucrats and international negotiators that the country would earn surplus allowances under the Kyoto Protocol [3].

Under the Protocol, the reduction commitments of countries are dependent on the development of the country. The Organization for Economic Cooperation and Development designation of countries was used to lump countries into categories including Annex I and non-Annex I. Annex I countries that ratified the Protocol are known as Annex B countries and are required to meet emission reduction targets. Non-Annex I countries are not required to meet emission targets but are eligible to host CDM projects whose offsets, known as Certified Emission Reductions can be used to meet reduction targets.

Some economies in transition, like Russia and the former Soviet Union, that are neither considered developed or developing countries must stabilize their average annual emissions between 2008-2012 at 1990 levels under the Kyoto Protocol. Eastern European countries have individual reduction targets that range from 5 to $8 \%$ below baseline year emission levels. Calculated cumulative surplus AAUs in the Kyoto commitment period 2008-2012 in literature is approximately 8-13 billion metric tons of greenhouse gases, which represent $6 \%$ of 1990 Annex I emissions [1,4,5]. On average, all Annex I countries only have to reduce their emissions 5.2\% below 1990 levels [6]; therefore, there are more surplus emissions than reductions necessary. And, assuming that countries take on reasonable targets they have discussed in negotiations, the carbon market news and analysis firm, Point Carbon, estimates that this surplus could fill assumed reduction targets until 2020, and there would still be 6.9 billion excess AAUs [7]. Because these AAUs that can be sold do not represent emission reductions that were made to comply with Kyoto targets, they are frequently dubbed "hot air" by critics of the use of these AAUs.

\section{AAU Trade Details}

\subsection{Trading Parties}

AAU trades historically occurred at the governmental level where AAUs purchased can be used to meet the country's obligations, but recent trends have shown an increasing number of trades among private entities. Within Europe, no AAUs are allowed for emitters' compliance obligations under the EU Emission Trading Scheme; however countries within the EU can use AAUs to fulfill their country-wide compliance obligations. In Japan, if the government agrees to the trade, individual companies can purchase AAUs from other governments in order to meet their reductions under Japan's Voluntary Emission Reduction Scheme (JVETS) that provides up-front financing for up to one-third of the total capital costs of emission reduction projects undertaken by industrial companies [8]. Also, carbon brokers and banks have begun to be involved in the market. Camco, a carbon offset project 
developer and aggregator, purchased AAUs from Hungary for resale to a Japanese company that participates in JVETS in April 2010 [9]. Dighton Carbon, Tawhaki International, Fortis Intertrust, Interblue, and various World Bank funds have also made AAU purchases [7,10]. Some market critics, however, believe that these intermediate firms are just helping to obscure the market, allowing for arbitrage and unmitigated corruption in some cases. An example of this type of corruption occurred in a trade of 15 million AAUs between the newly-created company Interblue and the Slovakian government for the cheap price of $€ 5.05$ per AAU. Interblue then resold these AAUs for $€ 8$ or more each [11]. Due to concerns over this type of resale of AAUs and the secrecy of private AAU transactions, the Ukrainian government canceled the two largest AAU deals ever agreed upon-one with Dighton Carbon for 100 million AAUs and another with Tawhaki International for 50 million AAUs. The Ukrainian Head of the National Environment Investment Agency now will only sell to governments wishing to purchase AAUs [12].

\subsection{Possible Future Demand}

As the end of the Kyoto Protocol's first commitment period nears in 2012, some countries that have not yet implemented federal legislation to curb greenhouse gases are at risk of not meeting their targets and may purchase AAUs to meet their demand since AAUs can be the cheapest compliance option, as will be later discussed. Using UNFCCC data from 2008 emission inventories, Canada will be approximately one billion metric tons short of its compliance obligation by 2012, if 2008 emission levels remain flat due to the recession and no significant land use or forestry activities to absorb emissions are undertaken. Using the same assumptions, Japan is expected to miss its target by 350 million metric tons, Australia will be 1.6 billion metric tons short, and New Zealand will be 93 million metric tons shy of its target [13]. In comparison to these countries that will have a shortfall, the EU-15 may not have a demand for AAUs since the EU-15 is on target to meet its Kyoto target of an $8 \%$ reduction of baseline emission levels by 2012 partially because of the recent recession, which decreased EU emissions between 2008 and 2009 by 6.9\%, [14] (This estimate takes into account emission removals due to land use change and forestry and use of planned purchases of flexible mechanisms).

\subsection{Price}

The price of AAUs is typically well below the price of a European Union Allowance, Certified Emission Reduction (CER), or Emission Reduction Unit (ERU) (from JI projects). Because these transactions are usually bilateral and not reported on a public exchange, the prices are usually confidential, and market information is sparse. The previously mentioned Slovakian trade with Interblue for $€ 5.05$ per AAU was also well below the $€ 15-20$ price of an EUA in Q4 of 2008 when the trade occurred $[11,15]$. Another trader reported that a trade between Poland as the seller and Ireland and the World Bank as the buyers occurred at $€ 10$ per AAU in December 2008 [8].

AAUs are the cheapest compliance option first and foremost because they do not always represent a real reduction in greenhouse gas emissions. Of course, the cheapest compliance option is going to be the one that requires no action. Use of surplus AAUs, known as "hot air" for compliance purposes can jeopardize the international reputation of countries [1]. While countries can technically fulfill Kyoto 
commitments with AAUs, doing so may draw negative attention from environmental watchdog groups and countries who have shunned surplus AAUs. Therefore, the demand for AAUs is less than other compliance instruments like CERs and ERUs.

AAUs are also cheaper because of the bureaucratic complexities that are a part of the CDM and JI. The upfront transaction costs to create a CDM project average between $\$ 70,000-\$ 110,000$ [16]. Therefore, large projects are more financially viable for crediting because they yield more reductions to cover these costs. As many of the large projects like HFC-23 mitigation that were most economically viable have already been developed and are currently under scrutiny, the least-cost CDM projects are drying up [17].

Joint Implementation (JI) projects also provide a means for cost containment, but there have been even less reductions created by JI projects due to the late 2008 start to this mechanism and the fact that each Emission Reduction Unit created under JI in a sector that has reduction targets requires that an AAU from the country's inventory be canceled so as to prevent double counting of the emission reduction. Therefore, there is a disincentive for countries to engage in projects that involve energy efficiency measures or implementation of renewable energy as the credits created take away from the allowances the government is able to allocate to its industrial sectors [18]. The UK has shunned these projects completely [19]. However, for countries like Russia and the post-Soviet States with excess AAUs, cancelling AAUs to create ERUs is not much of a penalty since the country has more AAUs than it needs to allocate to the industrial sectors [20].

\subsection{Volumes}

AAU trades are tracked by the International Transaction Log hosted by the UN. This log is public, but it only records transactions between countries. Individual account holders within country registries are not specified, and details about contracts for forward delivery or options are not included [7]. This opaque marketplace makes tracking difficult.

Currently, the United National Environment Programme's Capacity Development for the Clean Development Mechanism (CD4CDM) compiles information from Point Carbon, Bloomberg, and Reuters and logs trades on its JI Pipeline spreadsheet updated each month [21]. Thirty-three trades totaling 470 million AAUs were logged as of September 2010, but some of the trades were missing information like the quantity traded. During the second half of September 2010, the pipeline was revised to exclude 5 Ukrainian deals, three which were double counted and two aforementioned deals that were cancelled [19]. The revised number of AAU trades from CD4CDM was 190 million, which is closer to the total reported in an April 2010 paper funded by the Joanneum Research and the Center for Climate Change and Sustainable Energy Policy [1]. Figures 1 and 2 below show the participating parties and volume of trades that have been reported to CD4CDM as of 1 January 2011. 
Figure 1. Assigned amount unit (AAU) Sales [19].

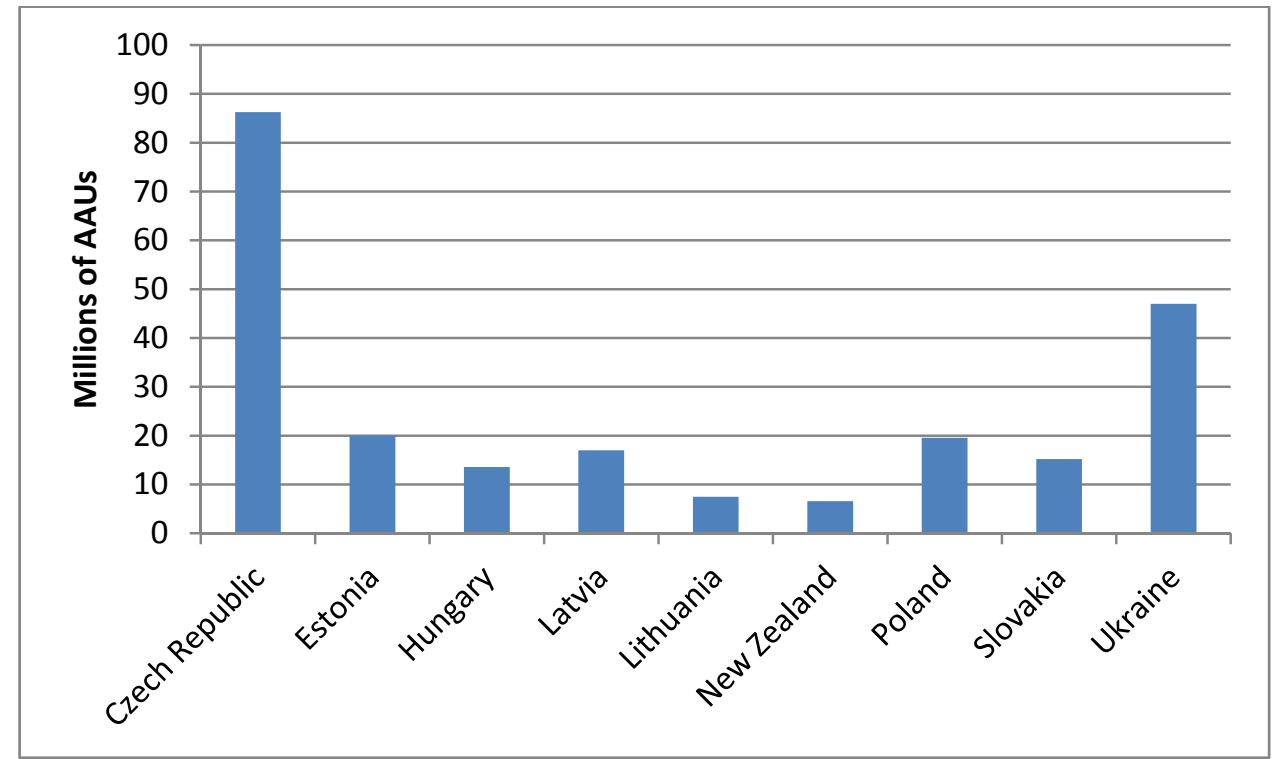

Figure 2. Assigned amount unit (AAU) Purchases [19].

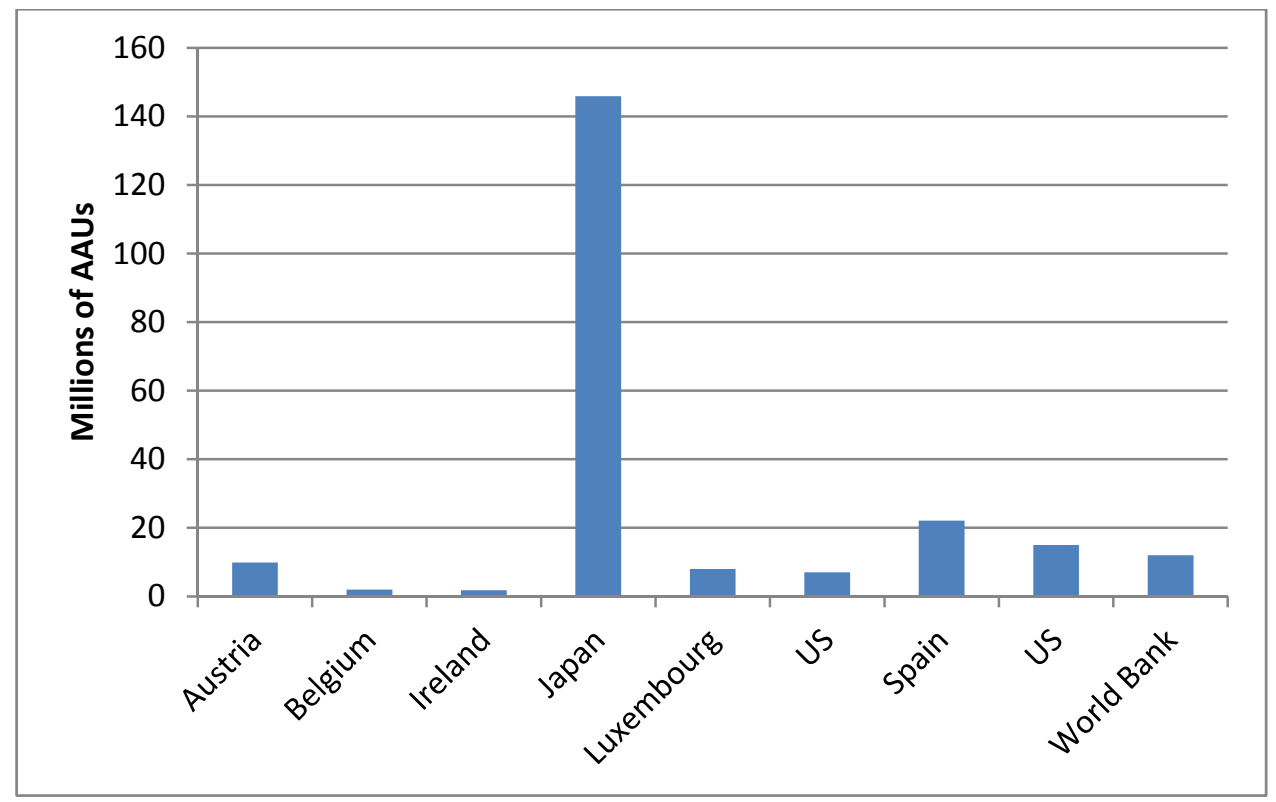

Despite the modest AAU sales to date, the overall size of the AAUs for sale is staggering. With an estimated 8-13 billion surplus AAUs, AAU trades could dwarf the current CDM market, which has only 2.88 billion metric tons expected by 2012, and the JI market, with 388 million metric tons expected by 2012 [10]. Global carbon markets in total resulted in only 8.7 billion tCO2 traded in 2009 [22].

Despite the potential to flood the market due to the volume of AAUs available, it is important to note that Annex I countries cannot fulfill 100\% of their demand for emission reductions through the purchase of AAUs. The supplementarity clause, set by the Kyoto Protocol Article 17, stipulates that international emission trading "shall be supplemental to domestic actions for the purpose of meeting quantified emission limitation and reduction commitments under that Article", but exact amounts of AAUs acceptable for fulfillment of compliance obligations are unavailable. Nonetheless, this supplementarity stipulation will prevent the full volume of surplus AAUs from being used before 
2012, even though surplus AAUs purchased now may be used in a post-Kyoto global framework as will be discussed later [23].

Another factor that will most likely limit the number of AAUs sold is the amount of AAUs that countries will be willing to sell before 2012. Despite the 13 billion AAU potential to be sold, Eastern European countries have made statements that they will only sell 1.9 billion AAUs, and Russia has not made mention of selling any AAUs or sold any to date, even though there is no Kyoto protocol rule preventing them from selling more prior to 2012. Taking into account global demand of 3.7 billion metric tons and CER and ERU supply expected by 2012, there will be a net shortfall of emission reductions from Annex I countries of only 1.3 million metric tons. Therefore, even with just 1.9 billion AAUs offered to market, there will be more supply than demand of AAUs [1].

Despite the supplementarity clause and the pledges of countries to sell only a portion of the available AAUs, market critics fear AAUs without closely monitored GISs still have the possibility of flooding the current Kyoto market or future global frameworks, creating massive environmental and financial implications [24].

\section{Environmental Impacts of AAU Trades with and Without GISs}

The voluntary nature of environmental activity to back up AAU trades, which leads to the low prices discussed in the previous section and compromises efforts to mitigate climate change, provides more evidence for why policy makers need to decide on the goal of AAU trading in the future. During the finalization of the rules of the Kyoto Protocol in 2001 at Marrakesh, Russia was in favor of and helped shape a scheme to provide green investment schemes (GISs) that funnel money from AAU trades into activities that facilitate emission reductions [25]. These schemes can be labeled as "hard" or "soft". Hard GISs attempt to provide measurable and quantifiable emission reduction schemes, and sometimes these reductions are desired on a one-to-one basis with AAUs sold. Examples of hard greening projects supported by Estonia include improvement of district heating networks, boiler house rehabilitation, industrial energy efficiency, and public transportation projects [1].

Soft GIS schemes, on the other hand, allow money to go into a general fund that supports activities that reduce or absorb emissions but do not necessarily provide a one-to-one AAU to emission reduction ratio [1]. Soft GISs are meant to support greenhouse gas reduction activities that take the form of energy efficiency programs, loan guarantees for projects that absorb or reduce emissions, or customer incentives to engage in activities that use less greenhouse gases. While these soft projects have an important role in greenhouse gas mitigation, they are typically left out of CDM or JI projects due to their inability to be proven additional to a "business-as-usual" scenario or to produce emission reductions that can be monitored and verified precisely [1]. AAUs sold from both hard and soft schemes are known as "greened" AAUs.

Countries have not been consistent in their public statements and actions about what qualifies as an acceptable domestic GIS. The Ukraine is now considering soft greening schemes whereas it previously stated that it would only accept hard greened projects. Hungary stated it supports only hard GIS projects, but it later announced that it may use AAUs for a budget crisis instead of emission reduction projects [8]. Hungary later reverted to its original position and said it would not use AAU revenues to support this budget crisis, but the country's reputation for selling high-quality AAUs was already 
marred. Poland, Romania, Slovakia, Bulgaria, Lithuania, and Russia have not finished setting up systems to administer GISs, but this lack of an infrastructure for GISs did not prevent Poland, Slovakia, and Lithuania from selling AAUs [1].

Even though GISs were a part of the design discussion, they are not required by the Kyoto Protocol. Therefore, whether or not they occur depends primarily on the preferences of the buyer and seller. Some buyers like Japan have stated publicly that they only support AAU trades that are backed up by GISs, but this statement is somewhat vague since the type of GIS supported is not specified. Even if the type of GIS was specified, the rules for what an eligible hard or soft GIS is and how reductions from it are monitored and verified are left unwritten. These rules are up to the discretion of each country; some countries have developed guidelines for eligible projects and a system for eligibility, monitoring, and verification of emission reductions while others have not tackled this challenge [1].

If one wanted to check the purchases of Japan to see that the AAUs purchased did actually come from trades that involved the creation of a GIS, he would find this information unavailable. The ITL only records trades between countries, not the details of the trade. Perhaps the complexity of AAU trades and the Kyoto architecture is too multifaceted for whistle-blowers and watchdog groups to have navigated this web well enough to demand more transparency in these governmental transactions. It is the taxpayers who typically support AAU purchases, despite the fact that they may not know what they are getting.

Unless previously arranged in a buying agreement, countries selling AAUs are under no international obligation to create GISs. And, an economist could argue that the Kyoto Protocol is operating exactly as it was intended without the creation of a GIS. Reductions are being made in the cheapest way possible, allowing for the cost containment that was the goal of IET. The 2012 goals of the Kyoto Protocol took into account the high emissions from Eastern European countries. Whether or not these emission targets are adequate to prevent catastrophic damage from climate change is another question.

Despite the design of the Kyoto Protocol to not require GISs for AAU trades, use of surplus AAUs could fail to meet emission reductions recommended by the Intergovernmental Panel on Climate Change (IPCC), which assesses the scientific, technical and socio-economic information relevant for understanding the risk of human-induced climate change. To meet a target of limiting global temperature increase to $2{ }^{\circ} \mathrm{C}$, compared to pre-industrial levels, greenhouse gas (GHG) concentrations in the atmosphere, in the long term, need to be kept below $450 \mathrm{ppm} \mathrm{CO}_{2}$ equivalency to have a mean probability of over $50 \%$ of achieving this target [26]. The IPCC has determined that, for such a target, reductions for developed countries would need to be in the range of 25 to $40 \%$ by 2020 compared to 1990 [27] while developing countries cut emissions between 15 to $30 \%$ of their 1990 emissions by 2020 [28]. Inclusion of the surplus AAUs in a post-2012 greenhouse gas reduction framework that is based on the pledges made by countries in the Copenhagen Accord would mean that developed countries would only need to cut their emissions by 6-11\% of 1990 levels to meet their targets [4]. These meager cuts deviate substantially from the $25-40 \%$ cuts recommended by the IPCC. 


\section{Economic Impacts of AAU Trades}

A lack of clarity on the policy goal of AAU trades has led not only to an undermining of greenhouse gas reductions, but it also has the potential to undermine the stability of carbon markets worldwide. AAU trades that are not backed by a green activity that provides a hard greening scheme have the ability to erode the price of carbon towards the end of the Kyoto compliance period. If a project is not required to produce any environmental benefit, then the opportunity for trades well below market price, which is set by the cost of making a metric ton of reduction elsewhere in the world, will abound. This situation has already occurred in some AAU trades such as the previously-mentioned trade of 15 million AAUs between Slovakia and the Swiss firm Interblue for the price of $€ 5.05$, one-third of the EUA price at the time [1]. Even if a GIS is preferred and required by the buyer, the scheme may not require hard greening. Therefore, since the cost of these AAUs from soft GISs do not represent the cost of making one metric ton of reduction, AAUs from soft GISs could still significantly undercut the price of emission reductions worldwide and cause the price of allowances to dive.

A price crash, as described above, occurred at the end of the first EU Emission Trading Scheme (ETS) in 2007 when compliance entities realized that the market was long and that it would be much easier than expected to meet reduction targets with the allowances they held. As a result, allowance prices plummeted from $€ 30$ per ton of $\mathrm{CO} 2$ in May of 2006 to just $€ 1$ toward the end of 2006 and 2007 [15]. As a result of this experience, the EU decided to allow unlimited banking of allowances between the second (2008-2012) and third (2013-2020) Emission Trading Scheme periods, which will help provide a more stable marketplace for allowances in Europe. Likewise, allowing for banking of AAUs will help reduce the threat of AAUs being dumped on the market near 2012 and an ensuing price crash, but allowing AAUs to be banked to the next period could threaten the environmental integrity of the next global treaty, as described in the previous section. Use of AAUs in future compliance regimes was debated in Copenhagen at the Conference of Parties in December 2009, and at Conference of Parties-16 negotiations in Cancún, Mexico in 2010, parties agreed on a "no change option" with respect to the surplus AAUs [29]. Therefore, AAUs can currently be banked into a future compliance period, even though this future regime does not yet exist.

The price of the European Union Allowance (EUA), which dominates global carbon markets with $73 \%$ of the trades in all global carbon markets, is somewhat sheltered from a price shock that would occur if excess AAUs were dumped on the market prior to the end of the first Kyoto commitment period in 2012 since AAUs are not allowed for compliance within the EU ETS [30]. However, because the European market is indirectly linked with international carbon markets through offsets trading, the use of cheap AAUs to meet compliance goals will have an attendant decrease in demand for CERs and ERUs from the countries that use the cheap AAUs. While entities within the EU are the primary CER and ERU buyers, Canada and Japan have purchased CERs from 10\% of the projects developed under CDM and 4\% under JI [10]. This demand may cease to exist, and the price of the CER and ERU may fall as project developers attempt to market their offsets to a more limited marketplace. As a result of these lower CER and ERU prices, compliance entities under the EU ETS may choose to source these cheaper offsets rather than buy allowances, which may then cause the price of EUAs to fall. 


\section{How to Handle AAU Surpluses in the Future}

The economic and environmental impacts of IET suggest that the AAU trading policy needs reforming in a post-2012 greenhouse gas framework. However, after considering the state of AAU trades and GIS development to date, it becomes clear that as the world enters the last two years of the Kyoto Protocol's compliance period, there will probably not be any dramatic steps taken on the part of AAU buyers like Japan to demand hard GISs as they struggle to meet emission reduction targets in the cheapest way possible. Even if the media successfully exposed this complicated subject and environmentalists pressured AAU buyers to support only transactions backed up by hard GISs, there is not enough time for a complex system of GIS eligibility screening, monitoring, and verification to occur. Therefore, there are likely to be price and environmental impacts related to high-volume, low-cost AAU trades that are made just before the end of the Protocol's first compliance period.

While there is no future global greenhouse gas accord or second compliance period to the Kyoto Protocol currently in place, countries did set forth targets for reductions by 2020 in the Copenhagen Accord and identified mechanisms to create a Kyoto successor in 2020 at the Conference of Parties 17 in Durban, South Africa in 2011. The lessons learned about AAU trades from excess allowances should guide the creation of the future framework design and country pledges. This section considers some solutions to the current AAU surplus and avoidance of the creation of surplus AAUs in the future.

\subsection{Selection of Baseline Year}

The origin of the surplus AAU situation lies with the choice of 1990 as a baseline year. Therefore, the question of baseline year selection for future accords is particularly important to clarify as advanced developing countries consider intensity-based reductions and targets for a future framework that may result in additional surplus AAU generation. Will advanced developing countries be able to negotiate an advantageous baseline year as Russia did? Given the diversity of advanced developing countries that include Brazil, Mexico, India, China, and Indonesia, it is unlikely that there is one year that would provide an advantageous baseline for all of them. Therefore, they may vie for individual baseline years.

While one might assume that 1990 will serve as the baseline year for all members of a future global framework, this may not be the case. Countries that submitted Copenhagen Accord targets used a mixture of 1990 and 2005 baseline years. Other countries, like Mexico, chose to put targets in terms of a comparison to future business-as-usual emissions, which are open to manipulation. Particularly concerning is the case of Russia and the Ukraine which have reduction pledges under the Copenhagen Accord that are above their baseline emissions, creating a situation where 2.2 billion more surplus AAUs would be created from Russia and 1.9 billion AAUs from the Ukraine [24,31]. Selection of the baseline year for future negotiations is likely to be contentious as it will have huge implications for how much a future accord will impact economies and the appearance of action on climate change. For example, the US's choice of a 2005 baseline year for its Copenhagen Accord target makes it appear as though its target is close to the EU target of between 20-30\% below 1990 levels [32]. If the US target is put in terms of 1990 emission levels, it is only a reduction of 4\% [33]. 
Perhaps instead of advocating for one particular baseline year, the UN should agree upon suitable baseline years for each country due to economic trends, civil war, and natural disasters. Hungary (average 1985-1987), Poland (1988) and Slovenia (1986) all used alternative baseline years for their Kyoto targets due to the collapse of the soviet socialist economy in the late eighties, which resulted in years with unusually low CO2 levels [34]. This approach, however, may just create more controversy as it would open up the floor for a debate of the chosen year.

Beyond the question of baseline year or years chosen, one must consider how recessions that occur after a baseline year are to be handled. It would be preferable to have one standardized way to handle recessions as occurred in the Former Soviet Union and Eastern Europe.

\subsection{Creation of Stricter and More Timely Targets}

Creation of reduction targets is similar to the choice of a baseline year as this is the result of a political process that involves negotiation. While choosing consistent baseline years and reduction targets for nations that are more or less at the same level of development is an important goal, nations often advocate for what is in their best interest rather than what will actually reduce emissions. Creating stricter targets for all Annex I countries, including economies in transition, would help absorb the surplus AAUs, if they were allowed to be carried over into a future compliance regime. However, this solution will not be politically feasible as it requires cuts deeper than all Annex I countries are willing to take on, as evidenced by the Copenhagen Accord targets [24].

In order to meet the aggressive targets that the IPCC deems necessary, targets for reductions could be set more frequently with shorter time horizons for completion. These new targets could reflect economic changes like recessions and the decrease in price of clean technologies. For example, in the US's Regional Greenhouse Gas Initiative, less than $60 \%$ of the allowances were sold since emitters hold close to the number of allowances that they will need for compliance from 2009-2011. This glut of allowances is due to the recent economic recession and fall in natural gas prices, which allowed some petroleum-burning facilities to switch to burning natural gas [35]. Several prominent non-profits are now calling for a revised cap on this market due to these market conditions [36]. Some market analysts might argue that if emissions decline due to contractions in economies, these reductions should count toward required targets since it could be prohibitively expensive for countries to cope with both an economic downturn and regulations that call for deeper emission cuts while others might argue that only emission reductions that were the outcome of a climate change plan or policy should count towards reduction goals. The long lag between when the Kyoto Protocol was drafted in 1997 and when it came into force in 2005 was part of the reason why a 1990 baseline year led to so many surplus AAUs. Having a more timely creation of target periods will help reduce the creation of unchallenging reduction targets and account for future recessions. This solution may include the creation of a new target for each country every five years in order to accurately reflect their current emissions.

A pitfall of this solution is that it does not provide the required amount of certainty necessary to make future investments in industries that are covered by regulation in the country. For example, investment in new energy capacity additions would be heavily contingent on the price of an allowance in the country. Usually, low carbon energy technologies cost more upfront to install. With a constantly changing allowance budget every five years or so, energy companies may not be able to make an 
informed decision about the least-cost energy additions that provide adequate power for their customers and result in emissions that are covered by their allowance budget.

It is important to note that the question of what to do about future recessions is moot if the creation of a cap that achieves the reductions necessary to reach the IPCC targets is set. However, transforming this scientific figure into a political reality and having enough confidence in the market to ensure that the cap is not surpassed has proven challenging.

\subsection{Restrictions on Use of Assigned Amount Units (AAUs) after Kyoto}

There are a number of ways to handle the already-created AAUs as they roll into the next greenhouse gas agreement. Use of a strategic reserve of AAUs, optimal banking of AAUs, taxation of AAU transactions, and prohibition of AAU use would all reduce the impacts of use of surplus AAUs, but not all of these solutions may be palatable to participating countries.

\subsubsection{Strategic Reserve}

In order to address the surplus AAU issue by limiting the AAUs banked from the Kyoto compliance period to the time period of the next global accord, the Kyoto Protocol's Article 3.13, which allows for unlimited banking of AAUs from the first to second commitment periods, would have to be revised [7]. Surplus AAUs from the first compliance period could be put into a strategic reserve that would be used only to meet domestic reductions for satisfaction of future targets, for a limited time period. Not only would this mechanism prevent AAUs from flooding the market and perhaps allow for cost containment for achievement of future domestic reduction goals, but a strategic reserve would permit some countries to maximize their financial gains over time. This solution would create the penalty of preventing the country with the surplus AAUs from earning money by selling AAUs to buyers abroad while meeting preliminary targets [24].

\subsubsection{Banking}

Alternatively, the country with surplus AAUs could engage in optimal banking where the number of AAUs allowed for sale in international markets is limited. In this way, the country with surplus AAUs would not have the ability to dump massive quantities of AAUs on the market at any given time and cause the market price to bottom out [37].

\subsubsection{Levies on AAU Transactions}

Retirement, acquisition, transfer, or carry-over of AAUs could carry a substantial levy that would discourage the use of AAUs. The revenue collected from these levies could be put towards mitigation activities [38].

\subsubsection{Prohibition of Future AAU Trades}

AAUs could be prohibited from being banked at all to meet future reduction targets post-2012. If this decision was made before 2012, it is likely that countries with excess AAUs would sell more than they planned on selling by 2012 and the current global carbon markets would be flooded with AAUs, 
causing EUA prices to drop and activities under CDM and JI to slow. If the decision was made after 2012, then Russia and other economies in transition may choose not to take part in a future accord since it ratified the Kyoto Protocol based on the rules that allowed the unlimited use of excess AAUs beyond 2012 [37].

All of these solutions have the potential to be quite controversial as AAUs are sovereign property; restrictions on their use could be seen as encroaching on the liberties of the members of a future global accord.

\subsection{Mandatory GISS}

Another solution would be for AAU trades to have mandatory GISs that yielded emission reduction ratios and followed a set of rules that was consistent in order to ensure that each GIS project was additional to a business-as-usual scenario of development and yielded real emission reductions that could be monitored and verified.

A system of this type would begin to resemble a CDM or JI project, and, like those projects, it would carry with it heavy administrative costs that would increase the cost of this type of trade. It would also require the coordination and approval of the host country as foreign verifiers would be called upon to validate the emission reduction assertions of the GIS project developers. Host country governments may not be willing to relinquish control over the money they have collected for these AAU sales to comply with strict GIS rules [1]. Also, the creation of a complex set of rules could lead to long delays in the successful set-up of programs to administer these safeguards just as internal politics delayed the issuance of ERUs from Russian JI projects [39].

Another possible problem with this solution is that AAU trades almost always occur before GISs are implemented. If the GIS did not yield the expected reductions, then a mechanism would have to be put in place to make sure the host country canceled AAUs to compensate for this failed project. Alternatively, the buyer could be responsible for cancelling AAUs from its account for GIS projects that failed. Either way, the nature of AAU trades would change as they would no longer be a low-risk, low-cost compliance strategy. A system of this sort would make AAU trades and the price of this compliance instrument more like Track 2 JI projects where the project is subject to review from the JI Supervisory Committee, an international, independent group that vets JI projects for eligibility and emission reductions created. The main difference would be that AAU trades would provide upfront financing for projects whereas JI projects only receive revenues once the ERUs have been created [18].

\section{Conclusions}

IET has been a key element of the cost-containing flexible mechanisms of the Kyoto Protocol and could prove to be a useful tool in the future. Before considering whether changes to AAU policies should be made, a clear goal of IET should be established. If the goal is to provide a low-cost compliance instrument for static emission targets, then perhaps no change to the current IET system should be implemented. If the goal is to allow for compliance flexibility but also maintain a stable

price of other compliance instruments and ensure that decreases in emissions due to recessions are not counted towards reduction goals, then a reformed version of the current IET like those proposed in this paper should be considered. 
If the goal of IET post-2012 remains to provide Annex B countries with a means "of fulfilling their commitments", then perhaps no changes to the way the AAUs are traded, baseline years chosen, and future targets should be required [40]. This purely market-driven cost containment measure will produce revenues for countries with surplus Assigned Amount Units (AAUs) and help reduce the cost of compliance, perhaps at the risk of not achieving sufficient greenhouse gas reduction. If the goal of IET is to address the market failures of the Kyoto Protocol and replace or complement Nationally Appropriate Mitigation Actions, then perhaps soft GISs that support sectors that cannot be traditionally supported by CDM or JI due to strict additionality, monitoring, and verification requirements should be required. If the goal of IET is to stimulate investment in a country and ensure that emission reductions are created for each AAU sold, then only GISs that include hard green projects that produce a one-to-one relationship of emission reductions created per AAU sold should be allowed, and a standardized way of evaluating and monitoring these projects should be created.

Deciding on the purpose of AAU trades in future greenhouse gas markets will help market designers to also make decisions about how to best control the impact that the surplus AAUs will have on the price of future compliance instruments and the environmental effectiveness of this legislation. To control the impact that surplus AAUs would have on future greenhouse gas markets, market designers could mandate that AAUs (1) always accompany hard or soft GISs; (2) be allowed for banking into the future compliance period; (3) not be allowed at all for use after 2012; (4) be allowed for only domestic emission reduction goals after 2012; (5) be allowed for limited trades; or (6) be taxed heavily upon retirement, acquisition, transfer, or carry-over [7]. The scenario selected will be determined by the overall policy goal for AAU trades in a future framework.

It is essential that a decision on the status of surplus AAUs for a post-Kyoto framework be made quickly as it will have implications for 2012 carbon prices and countries with surplus AAUs will move to either sell them on the market or hold them for future compliance periods. In the absence of a decision, countries with AAUs to sell may take advantage of the lack of regulation on GISs and simply dump AAUs with no environmental backing on the market. In the process of making the Kyoto Protocol palatable to all countries by providing a high degree of sovereignty to countries in their implementation of rules to support AAU trades, market designers have created the risk of undermining the entire market.

\section{References}

1. Tuerk, A.; Frieden, D.; Sharmina, M.; Schreiber, H.; Ürge-Vorsatz, D. Working Paper Green Investment Schemes: First Experiences and Lessons Learned; Joanneum Research and Center for Climate Change and Sustainable Energy Policy of the Central European University: Graz, Austria, 2010.

2. United Nations Framework Convention on Climate Change (UNFCCC). Kyoto Protocol Base Year Data; 2008. Available online: http://unfccc.int/ghg_data,kp_data_unfccc/ base_year_data/items/4354.php (accessed on 19 September 2011).

3. Korppoo, A. Forging alliance with Russia: The example of a green investment scheme. Clim. Policy 2003, 2, 67-76. 
4. den Elzen, M.G.J.; Roelfsema, M.; Slingerland, S. Dealing with surplus emissions in the climate negotiations after Copenhagen: What are the options for compromise? Energy Policy 2010, 38, 6615-6628.

5. Rogelj, J.; Nabel, J.; Chen, C.; Hare, W.; Markmann, K.; Meinshausen, M.; Schaeffer, M.; Macey, K.; Höhne, N. Copenhagen accord pledges are paltry. Nature 2010, 464, 1126-1128.

6. Springer, U. The market for tradable GHG permits under the Kyoto Protocol: A survey of model studies. Energy Econ. 2003, 25, 527-551.

7. Point Carbon. Assigned Amount Unit: Seller, Buyer Analysis and Impact on Post-2012 Climate Regime; Climate Action Network Europe: Brussels, Belgium, 2009.

8. Szabo, M. Governments keep hunting for cheap $\mathrm{CO}_{2}$ credits. Carbon Offsets Daily 3 March 2009.

9. Peto, S. Hungary receives 6 mln t AAU offer from UK's Camco. Reuters 6 April 2010.

10. Capacity Development for the Clean Development Mechanism (CD4CDM). CDM Pipeline; UNEP Risoe Centre: Rosklide, Denmark, 2010. Available online: http://cd4cdm.org/ (accessed on 19 September 2011).

11. Balogová, B. New revelations blow lid on interblue puzzle. The Slovak Spectator 29 March 2010. Available online: http://spectator.sme.sk/articles/view/38358/2/new_revelations_blow_lid_ on_interblue_puzzle.html (accessed on 19 September 2011).

12. Point Carbon. Ukranian calls time on controversial AAU deal with NZ firm. Carbon Market Australia-New Zealand 6 September 2010.

13. United Nations Framework Convention on Climate Change (UNFCCC). Total GHG Equivalent Emissions with Land Use, Land-Use Change and Forestry; 2008. Available online: $\mathrm{http}: / /$ unfccc.int/ghg_data/ghg_data_unfccc/time_series_annex_i/items,3842.php (accessed on 19 September 2011).

14. European Environment Agency (EEA). Tracking Progress towards Kyoto and 2020 Targets in Europe, Report 7; EEA: Copenhagen, Denmark, 2010.

15. Point Carbon. Historical Prices, accessed through member subscription on website. Thomson Reuters Point Carbon 20 September 2009.

16. UNDP. Transaction costs, efficiency and supportive governance. In The Clean Development Mechanism: A User's Guide; Chapter 5; United Nations Development Program (UNDP): New York, NY, USA, 2003.

17. Gronewold, N. CDM critics demand investigation of suspect offsets. New York Times 14 June 2010.

18. Korppoo, A.; Gassan-zade, O. Joint Implementation: Looking Back and Forward; Climate Strategies: Cambridge, UK, 2008.

19. Capacity Development for the Clean Development Mechanism (CD4CDM). JI Pipeline; 2011. Available online: http://cd4cdm.org/ (accessed on 19 September 2011).

20. Baker \& McKenzie. What is the Tract 1 Process? JI Rulebook; 2011. Available online: http://www.jirulebook.org/track1 (accessed on 19 September 2011).

21. Fenhann, J. Personal Communication, Risø National Laboratory for Sustainable Energy, Technical University of Denmark, 2010.

22. Kossoy, A.; Ambrosi, P. State and Trends of the Carbon Market 2010; Carbon Finance Unit, World Bank: Washington, DC, USA, 2010. 
23. Carbon Markets and Investors Association (CMIA). Post-2012 Trading and Transfer of Assigned Amount Units; 2010. Available online: http://www.cmia.net/LinkClick.aspx?fileticket= JSNYsa_Z3bc\%3D\&tabid=39\&language=en-US (accessed on 19 September 2011).

24. den Elzen, M.G.J.; Roelfsema, M.; Singerland, S. Too Hot to Handle? The Emission Surplus in the Copenhagen Negotiations; Netherlands Environmental Assessment Agency (PBL): Bilthoven, The Netherlands, 2009.

25. Tangen, K.; Korppoo, A.; Berdin, V.; Sugiyama, T.; Egenhofer, C.; Drexhage, J.; Pluzhnikov, O.; Grubb, M.; Legge, T.; Moe, A.; et al. A Russian Green Investment Scheme: Securing Environmental Benefits from International Emissions Trading; Climate Strategies: Cambridge, UK, 2001.

26. Meinshausen, M. What does a $2{ }^{\circ} \mathrm{C}$ target mean for greenhouse gas concentrations? A brief analysis based on multi-gas emission pathways and several climate sensitivity uncertainty estimates. In Avoiding Dangerous Climate Change; Schellnhuber, H.J., Cramer, W., Nakicenovic, N., Wigley, T., Yohe, G., Eds.; Cambridge Press: Cambridge, UK, 2006; pp. 265-280.

27. Gupta, S.; Tirpak, D.A.; Burger, N.; Gupta, J.; Höhne, N.; Boncheva, A.I.; Kanoan, G.M.; Kolstad, C.; Kruger, J.A.; Michaelowa, A.; et al. Policies, instruments and co-operative arrangements. In Climate Change 2007: Mitigation. Contribution of Working Group III to the Fourth Assessment Report of the Intergovernmental Panel on Climate Change; Metz, B., Davidson, O.R., Bosch, P.R., Dave, R., Meyer, L.A., Eds.; Cambridge University Press: Cambridge, UK, 2007.

28. den Elzen, M.G.J.; Höhne, N. Reductions of greenhouse gas emissions in Annex I and non-Annex I countries for meeting concentration stabilisation targets. Clim. Change 2008, 91, 249-274.

29. Cancún Highlights; Earth Negotiations Bulletin; International Institute for Sustainable Development: New York, NY, USA, December 2010. Available online: www.iisd.ca/ vol12/enb12490e.html (accessed on 19 September 2011).

30. Ramming, I.; Kleinwort, D.; Carbon Trade and Finance. AAU Trading and the Impact on Kyoto and EU Emissions Trading: Before the Flood or Storm in a Tea-cup? International Emissions Trading Association Greenhouse Gas Market Report; Dresdner Kleinwort: London, UK, September 2008.

31. United Nations Environment Programme. UNEP Emissions Gap Report: Are the Copenhagen Accord Pledges Sufficient to Limit Global Warming to 2 or $1.5{ }^{\circ}$ C? 2010. Available online: www.unep.org/publications/ebooks/emissionsgapreport (accessed on 19 September 2011).

32. World Resource Institute (WRI). Summary of GHG Reduction Pledges Put Forward by Developing Countries; 2010. Available online: http://pdf.wri.org/summary_of_non_annex1_ pledges_2010-06.pdf (accessed on 19 September 2011).

33. Bilello, D.U.S. Commits to greenhouse gas cuts under copenhagen climate accord. Scientific American January 2010. Available online: http:/www.scientificamerican.com/article.cfm?id=uscommits-to-greenhouse-gas-cuts-under-copenhagen-accord (accessed on 19 September 2011).

34. Stariha, M.; Klemenc, A. Evaluation of Activities Implemented Jointly in Slovenia, Case Study from Capacity for Climate Protection in Central and Eastern Europe; The Regional Environmental Center for Central and Eastern Europe: Szentendre, Hungary, 2000. Available online: http://archive.rec.org/Climate/casestudies/Slovenia.html (accessed on 19 September 2011). 
35. Lawson, A.; Mazzacurati, E. RGGI: A long life to come? Point Carbon Analysis 6 December 2010.

36. Point Carbon. Key groups call for RGGI revisions. Carbon Markets Daily 13 January 2011.

37. Korppoo, A.; Spencer, T. Pressing the Surplus Reset Button: Approaching the AAU Issue with Strategic Compliance Reserve and Optimized Trading; Climate Strategies: Cambridge, UK, 2010.

38. Alliance of Small Island States. In-Session Workshop on Scale of Emission Reductions, Ad hoc Working Group on Further Commitments for Annex I Parties under the Kyoto Protocol, 13th Session; Bonn, Germany, 2010.

39. Szabo, M. Russia approves first $\mathrm{CO}_{2}$ offset projects. Reuters 26 July 2010.

40. United Nations Framework Convention on Climate Change. Kyoto Protocol to the United Nations Convention on Climate Change; Article 17; 1997. Available online: http://unfccc.int/ kyoto_protocol/items/2830.php (accessed on 19 September 2011).

(C) 2012 by the authors; licensee MDPI, Basel, Switzerland. This article is an open access article distributed under the terms and conditions of the Creative Commons Attribution license (http://creativecommons.org/licenses/by/3.0/). 